\title{
Aberrant expression of collagen family genes in the brain regions developing under agonistic interactions in male mice
}

\author{
Smagin D.A., Galyamina A.G., Kovalenko I.L., Babenko V.N.*, Kudryavtseva N.N.* \\ Laboratory of Neuropathology Modeling, Institute of Cytology and Genetics, Siberian Branch \\ of Russian Academy of Sciences, Novosibirsk, Russia
}

Summary

As previously established, chronic agonistic interactions lead to the development of depression-like state under social defeat stress in the defeated mice and pathology of aggressive behavior in the winning mice. According to the numerous research data, these psychopathological states are accompanied by tremendous molecular and cellular changes in the brain. The paper aimed to study the influence of 20-day period of agonistic interactions on the expression mode of collagen family genes, encoding the proteins, which are basic components of extracellular matrix (ECM), in the different brain regions of mice using the RNA-Seq database. Most of the differentially expressed collagen genes were upregulated in the hypothalamus and striatum of chronically aggressive and defeated mice and in the hippocampus of the defeated mice. In the ventral tegmental area the most genes were downregulated in both experimental groups. It has been assumed that aberrant expression of collagen genes induced by long experience of agonistic interactions can indicate defects of ECM specific for brain regions in mice with alternative social experiences. This study first shows remodeling of molecular base in the ECM under development of experimental psychoneuropathologies.

Keywords: collagen genes, social defeats, depression, repeated aggression, extracellular matrix, brain regions

Corresponding authors: Kudryavtseva N.N., n.n.kudryavtseva@gmail.com; Babenko V.N., bob@bionet.nsc.ru

\section{Introduction}

According to the research data, chronic agonistic interactions lead to the development of behavioral psychopathologies. They include the development of mixed anxiety/depressionlike states in defeated male mice [Kudryavtseva et al. 1991; Kudryavtseva \& Avgustinovich, 1998; Berton et al. 2006; Bondar et al. 2009; Galyamina et al. 2017], similar to those in humans, and psychosis-like behavior in the repeatedly aggressive mice [Kudryavtseva 2006; Kudryavtseva et al. 2014; Ibrahim et al. 2016]. After daily agonistic interactions, the behaviors of both social groups are crucially changed. Depressive males demonstrated total behavioral deficit (low locomotor and exploratory activity, immobility in different experimental situations), avoidance of social contacts and reduced communication, anhedonia and generalized anxiety. Chronically aggressive mice displayed enhanced aggression, high impulsivity and anxiety, as well as impaired social recognition, hyperactivity and stereotypic behaviors. Aggressive motivation prevailed in all social interactions. 
bioRxiv preprint doi: https://doi.org/10.1101/276063; this version posted March 4, 2018. The copyright holder for this preprint (which was not certified by peer review) is the author/funder. All rights reserved. No reuse allowed without permission.

It was established that under chronic social defeat stress the adult brain undergoes numerous molecular and cellular changes [Kudryavtseva et al. 2004; Berton et al. 2006; Boyarskikh et al. 2013]. Analyzing the whole transcriptome in brain of depressive mice, we have found changes in the expression of serotonergic [Smagin et al. 2013; Kudryavtseva et al. 2017], dopaminergic [Kovalenko et al. 2016], glutamatergic and GABAergic [Smagin et al. 2017; Galyamina et al. 2017] genes as well as ribosomal and mitoribosomal genes [Smagin et al. 2016a; Smagin et al. 2016b] in different brain regions. Changes in DNA methylation, histone acetylation and chromatin remodeling often accompany these changes [Hollis et al. 2010; Kenworthy et al. 2014], as well as decreases in hippocampal neurogenesis rates [Ferragud et al. 2010; Lagace et al. 2010; Van Bokhoven et al. 2011] in defeated mice. We found changes in activity of monoaminergic gene expression in brain regions, activation of cell proliferations in the hippocampus, as well as growth of new neurons under repeated experience of aggression in male mice [Kudryavtseva et al. 2004; Bondar et al. 2009; Filipenko et al. 2001; Smagin et al. 2013; Smagin et al. 2015; Kudryavtseva et al. 2017]. Using the transcriptome analysis on RNA-seq data this report is aimed to study the changes of the collagen family gene expression in the 5 brain regions of the male mice with alternative social experience in daily agonistic interactions over a 20-day period.

There are 28 collagen subfamilies (Col1 - Col28) comprising 45 collagen genes total in mouse genome [Myllyharju \& Kivirikko 2004; Gordon et al. 2010; Ricard-Blum, 2011; Seppänen et al, 2006, Seppänen et al, 2007]. The collagen family genes $\left(\mathrm{Co}^{*}\right)$ encode collagen proteins which manifest the predominant glycoproteins group of extracellular matrix (ECM) constituting the main component of connective tissue in mammals [Myllyharju \& Kivirikko 2004; Gordon et al 2010; Ricard-Blum 2011]. Collagen is a fibrous protein found in vertebrates representing the major element of skin, bone, tendon, cartilage, blood vessels and teeth. The role of collagens is forming fibrils and assembling into elongated fibers in the ECM [Fox 2008].

In the brain tissue a fibrillar collagen is apparently absent [Hubert et al. 2009], while the collagens function as structural and active adhesion molecules [Myllyharju \& Kivirikko 2004; Kadler et al. 2007]. Being the structural components of extracellular matrix, collagens are also involved in neuronal development of the brain and play a role in regulation of axonal outgrowth, and synaptic differentiation [Sertie, et al. 2000; Schneider \& Granato 2006; Fox et al. 2007], neural maturation [Fox et al. 2007; Heffron et al. 2009], synaptogenesis and establishment of brain architecture [Hubert et al. 2009; Chernousov et al. 2006]. Some of the collagen proteins are expressed by neurons [Claudepierre et al. 2005; Hashimoto et al. 2002; Sund et al. 2001].

Most CNS pathologies associated with collagens are related to neurodevelopment. For example, it was shown that collagen type IV promotes the differentiation of neuronal progenitors and inhibits astroglial differentiation in cortical cell cultures [Ali et al. 1998]. Postmortem human studies showed that collagen type XVII is widely expressed in the brain and is located primarily in the soma and proximal axons of neurons in contrast to glial cells, which do not express this collagen [Seppänen et al. 2007]. Collagen XVI may act as a substrate for adhesion and invasion of connective tissue tumor cells. Alteration of tissue location and expression level appears to promote tumorigenesis and inflammatory reactions [Grässel \& Bauer 2013]. Thus, altering the cell-matrix interaction through collagen XVI might be a molecular mechanism to further augment the invasive phenotype of glioma cells. It is supposed, that collagen XVI plays a decisive role in the interaction of connective tissue cells with their ECM, which is impaired in pathological situations. Amyloid-beta peptides, widely presumed to cause Alzheimer's disease, increased mouse neuronal expression of collagen $\mathrm{VI}$ [Cheng et al. 2009]. Authors discovered that the cellular source of the collagen VI is neurons. Collagen IV proteins were increased in Alzheimer's disease patients in frontal and temporal cortex. Significant ECM changes occur during the early stages of this disease [Lepelletier et al. 2017]. Col25a1 alleles have been associated with increased risk for Alzheimer's disease [Forsell et al. 2010]. In these patients extracellular collagenous Alzheimer amyloid plaque component [Hashimoto et al. 2002], which is extracellular part of the transmembrane collagen XXV, is expressed by neurons. Interestingly, over-expression of 
bioRxiv preprint doi: https://doi.org/10.1101/276063; this version posted March 4, 2018. The copyright holder for this preprint (which was not certified by peer review) is the author/funder. All rights reserved. No reuse allowed without permission.

the Col25a1 gene in neurons in transgenic mice leads to Alzheimer's disease-like brain pathology [Tong et al. 2010]. It has been supposed that enhanced expression of the ECM related with cell adhesion genes, Col8a1 in particular, in the prefrontal cortex may affect cortical neural plasticity, including morphological neuronal changes and the afferent and/or efferent neural pathways participating in stress-related emotional behavioral patterns [ $\mathrm{Li}$ et al. 2013]. All these data indicate the possible role of $\mathrm{Col}^{*}$ family genes in different neurological disorders, however little known about reaction of brain $\mathrm{Col}^{*}$ genes expression on chronic functional uploads and in psychoemotional disorders.

\section{Materials and Methods}

\section{Animals}

Adult male mice C57BL/6J was obtained from Animal Breeding Facility, Branch of Institute of Bioorganic Chemistry of the RAS (ABF BIBCh, RAS), Pushchino, Moscow region. Animals were housed under standard conditions (12:12 hr light/dark regime starting at 8:00 am, at a constant temperature of $22+/-2^{\circ} \mathrm{C}$, with food in pellets and water available ad libitum). Mice were weaned at three weeks of age and housed in groups of 8-10 in standard plastic cages. Experiments were performed with 10-12 week old animals. All procedures were in compliance with the European Communities Council Directive 210/63/EU on September 22, 2010. The study was approved by Scientific Council N 9 of the Institute of Cytology and Genetics SD RAS of March, 24, 2010, N 613 (Novosibirsk).

\section{Generation of alternative social behaviors under agonistic interactions in male mice}

Prolonged negative and positive social experience, social defeats and wins, in male mice were induced by daily agonistic interactions [Kudryavtseva, 1991; Kudryavtseva et al. 2014]. Pairs of weight-matched animals were each placed in a cage $(14 \times 28 \times 10 \mathrm{~cm})$ bisected by a perforated transparent partition allowing the animals to see, hear and smell each other, but preventing physical contact. The animals were left undisturbed for two or three days to adapt to new housing conditions and sensory contact before they were exposed to encounters. Every afternoon (14:00-17:00 p.m. local time), the cage lid was replaced by a transparent one, and $5 \mathrm{~min}$ later (the period necessary for individuals' activation), the partition was removed for 10 minutes to encourage agonistic interactions. The superiority of one of the mice was firmly established within two or three encounters with the same opponent. The superior mouse would be attacking, biting and chasing another, who would be displaying only defensive behavior (sideways postures, upright postures, withdrawal, lying on the back or freezing). As a rule, aggressive interactions between males are discontinued by lowering the partition if the sustained attacks has lasted 3 min (in some cases less) thereby preventing the damage of defeated mice. Each defeated mouse (defeater, loser) was exposed to the same winner for three days, while afterwards each loser was placed, once a day after the fight, in an unfamiliar cage with an unfamiliar winner behind the partition. Each winning mouse (winners, aggressive mice) remained in its original cage. This procedure was performed once a day for 20 days and yielded an equal number of the winners and losers.

Three groups of animals were used: 1) Controls - mice without a consecutive experience of agonistic interactions; 2) Losers - chronically defeated mice; 3) Winners chronically aggressive mice. The losers and winners with the most expressed behavioral phenotypes were selected for the transcriptome analysis. The winners and losers, 24 hours after the last agonistic interaction, and the control animals were simultaneously decapitated. The brain regions were dissected by one experimenter according to the map presented in the Allen Mouse Brain Atlas (http://mouse.brain-map.org/static/atlas). All biological samples were placed in RNAlater solution (Life Technologies, USA) and were stored at $-70^{\circ} \mathrm{C}$ until sequencing. 
bioRxiv preprint doi: https://doi.org/10.1101/276063; this version posted March 4, 2018. The copyright holder for this preprint (which was not certified by peer review) is the author/funder. All rights reserved. No reuse allowed without permission.

The brain regions were selected for the analysis based on their functions and localization of neurons of neurotransmitter systems. These are as follows: the midbrain raphe nuclei, a multifunctional brain region, which contains the bodies of serotonergic neurons; the ventral tegmental area (VTA), which contains the bodies of dopaminergic neurons, is widely implicated in natural reward circuitry of the brain and is important for cognition, motivation, drug addiction, and emotions relating to several psychiatric disorders; the striatum, which is responsible for the regulation of motor activity and stereotypical behaviors and is also potentially involved in a variety of cognitive processes; the hippocampus, which belongs to the limbic system, is essential for memory consolidation and storage, and plays important roles in neurogenesis and emotional mechanisms; and the hypothalamus, which regulates the stress reaction and many other physiological processes.

\section{RNA-Seq}

We used the methods described earlier [Smagin et al. 2016a; Smagin et al. 2016b]. The collected samples were sequenced at JSC Genoanalytica (www.genoanalytica.ru, Moscow, Russia), and the mRNA was extracted using a Dynabeads mRNA Purification Kit (Ambion, Thermo Fisher Scientific, Waltham, MA, USA). cDNA libraries were constructed using the NEBNext mRNA Library PrepReagent Set for Illumina (New England Biolabs, Ipswich, MA USA) following the manufacturer's protocol and were subjected to Illumina sequencing. More than 20 million reads were obtained for each sample. The resulting "fastq" format files were used to align all reads to the GRCm38.p3 reference genome using the TopHat aligner [Trapnel et al. 2013]. DAVID Bioinformatics Resources 6.7 (http://david.abcc.ncifcrf.gov) was used for the description of differentially expressed gene ontology. The Cufflinks program was used to estimate the gene expression levels in FPKM units (fragments per kilobase of transcript per million mapped reads) units and subsequently identify the differentially expressed genes in the analyzed and control groups. Each brain area was considered separately for 3 vs 3 animals. Genes were considered differentially expressed at $P \leq 0.05$ and for multiplied comparisons $q<0.05$.

We have previously conducted studies of gene expression in males in similar experiments using the RT-PCR method with larger number of samples for each compared experimental group, i.e., winners and losers (> 10 animals). The direction and extent of changes in expressions of the Tph2, Slc6a4, Bdnf, Creb1, and Gapdh genes in the midbrain raphe nuclei of males compared with the control produced by two methods, including RTPCR [Smagin et al. 2013; Boyarskikh et al. 2013] and RNA-Seq [Kudryavtseva et al., 2017], are generally consistent. In order to cross-validate the our results obtained, we employed the unique resource from Barres Lab, Stanford University, USA [Zhang et al. 2014] and found highly concordant with our RNA-Seq data pool [Babenko et al. 2017]. As additional crossvalidation may be considered positive correlation $(r=0.74$, $\mathrm{df}=42, p<10 \mathrm{E}-4)$ between FPKM values of $\mathrm{Col}^{*}$ family genes in our experiment and in the experiment of Kadakkuzha et al. [2015] in the hippocampus of C57BL/6J mice. These findings suggest that transcriptome analyses of the data provided by the ZAO Genoanalitika (http://genoanalytica.ru, Moscow) have been verified, and this method reflects the actual processes that occur in the brain under our experimental paradigm.

The Human Gene Database (http://www.genecards.org/); Online Mendelian Inheritance in Man database (OMIM, http://omim.org/); Human disease database (MalaCards, http://www.malacards.org) were used for the description and analysis of the data obtained.

\section{Statistical analysis}

For the transcriptomic data, a Principal Components (PC) analysis was conducted using the XLStat software package (www.xlstat.com). It was based on a Pearson correlation metric calculated on the FPKM value profiles of 49 analyzed genes. Agglomerative Hierarchical Clustering (AHC) was performed on the same data with the XLStat software package. We also used a Pearson correlation as a similarity metric for the AHC analysis. The agglomeration method comprised an unweighted pair-group average. 


\section{Results and discussion}

Data of the RNA-Seq profiling in FPKM units for 49 collagen genes, including Colgalt1 and Colgalt2 (collagen beta(1-O)galactosyltransferase 1 and 2); Colq (collagen-like tail subunit of asymmetric acetylcholinesterase; Adipoq (adiponectin, C1Q and collagen domain containing, mRNA). Additionally, Ccbe1 (collagen and calcium binding EGF domains 1, mRNA), as well as procollagen genes (P4ha1, P4ha2, P4ha3, Pcolce, Pcolce2, Plod1, Plod2, Plod3) were considered.

Analyzing whole transcriptome data in the hypothalamus, midbrain raphe nuclei, hippocampus, ventral tegmental area (VTA), and striatum, we found similar and different changes in the expression of $\mathrm{Co}^{*}$ family genes in brain regions of male mice with alternative social experience of agonistic interactions (Table 1 ).

\begin{tabular}{|c|c|c|c|c|c|}
\hline & MRN & HPC & VTA & STR & HPT \\
\hline \multicolumn{6}{|l|}{ Winners } \\
\hline Genes, N & 6 & 5 & 12 & 5 & 19 \\
\hline Upregulation & 2 & 2 & 0 & 5 & 19 \\
\hline $\begin{array}{l}\text { Downregulation } \\
\text { Losers }\end{array}$ & 4 & 3 & 11 & 0 & 0 \\
\hline Genes, N & 8 & 15 & 9 & 20 & 19 \\
\hline Upregulation & 4 & 14 & 2 & 17 & 16 \\
\hline Downregulation & 4 & 1 & 7 & 3 & 3 \\
\hline
\end{tabular}

The most of $\mathrm{Col}^{*}$ genes that changed their expression were found in the hypothalamus (19 genes in both groups), hippocampus and striatum (15 and 20 genes, respectively, in the losers). The minority of $\mathrm{Col}^{*}$ differentially expressed genes were found in the midbrain raphe nuclei ( 6 and 8 genes in the winners and losers, respectively), in the hippocampus and striatum (for both 5 genes) in the winners and in the VTA (12 and 9 genes in the winners and losers, respectively). The most of differentially expressed genes of $\mathrm{Col}^{*}$ family in the hypothalamus of the winners and losers as well as in the striatum and hippocampus of the losers were upregulated. In the VTA these genes were downregulated in mice of both groups. (Full list of differentially expressed genes in the winners and losers in different brain regions are given in the Section Results, and in Supplement: Table 1 and additional statistics for differentially expressed $\mathrm{Col}^{*}$ genes in brain regions.

In the hypothalamus differentially expressed Col4a2, Col5a3, Col9a2, Col9a3, Col11a2, Col16a1, Col18a1, Col22a1, Col23a1, Col24a1, Col27a1 and Plod3 genes were upregulated in both social groups (Fig 1; Supplement, Table 1). Changes of the Col4a1, Col6a3, Col11a1, Col15a1, Col26a1, and Plod1 expression were upregulated and Col3a1, Col13a1 and Plod2 genes were downregulated specifically in the losers.

The expression of the Col1a1, Col4a5, Col4a6, Col5a1, Col6a1, Col6a2, Col6a4 and Pcolce genes was specifically upregulated in the winners. Expression of the Col4a2, Col9a2, and Col16a1 and its changes were maximal in the both social groups. The Col1a2 gene was upregulated in the winners and downregulated in the losers.

The upregulation of most $\mathrm{Col}^{*}$ genes in the hypothalamus of the winners and losers may be the response to the chronic social stress inducing development of anxiety in both participants of social conflicts [Kudryavtseva \& Avgustinovich 1998; Kudryavtseva et al. 
2002]. Earlier we found similar upregulation of most amount of ribosomal $\left(R p /^{*}\right.$ and $R p s^{*}$ families) and mitochondrial ribosomal (Mrp/* and $\mathrm{Mrps}^{*}$ families) genes in the hypothalamus of the winners and losers [Smagin et al. 2016a; Smagin et al. 2016b]. It's therefore natural to suppose the coexpression or joint expression elevation of numerous genes developing under chronic social stress of agonistic interactions.

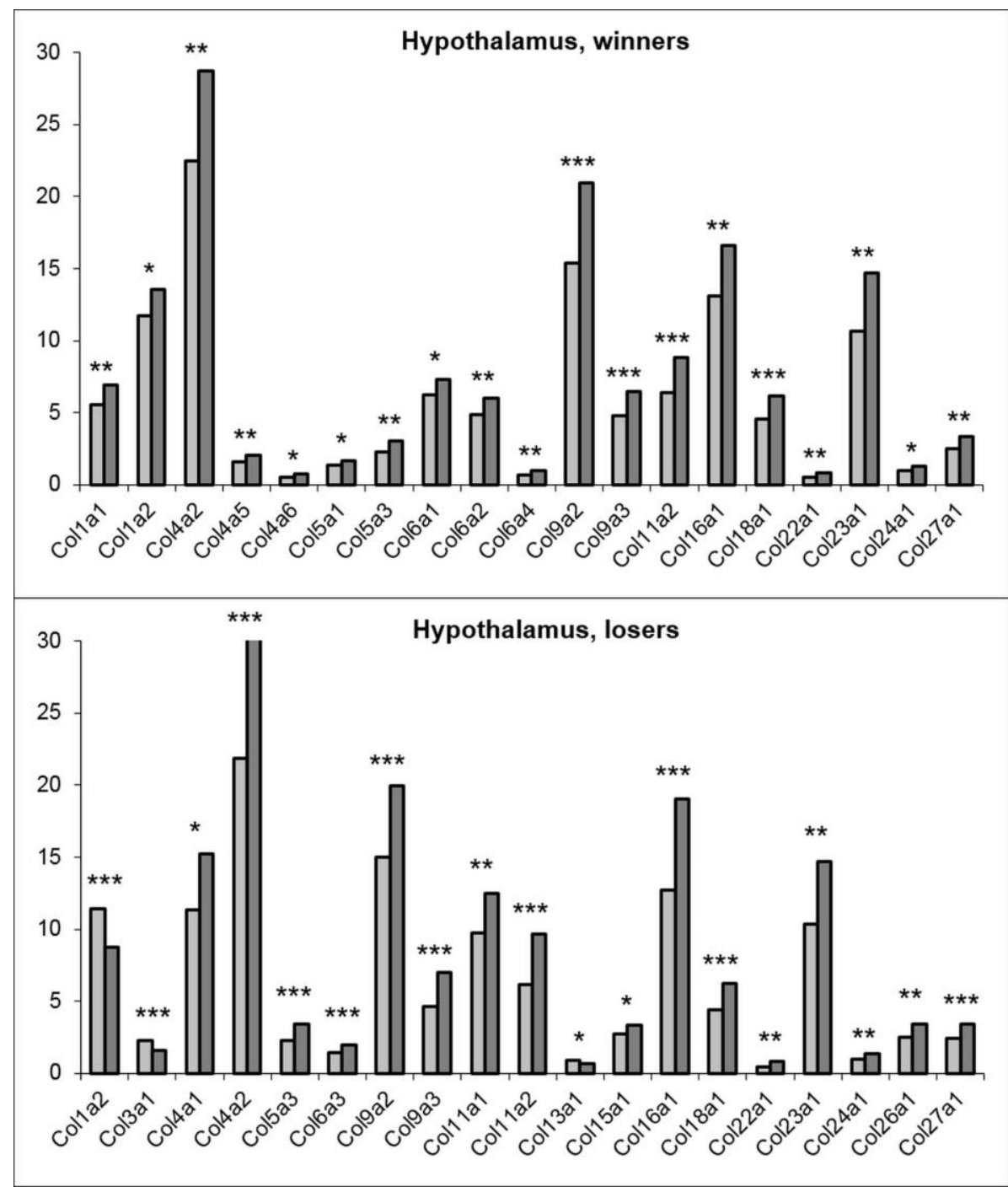

Figure 1. The differentially expressed collagen $\mathrm{Col}^{*}$ family genes in the hypothalamus of mice with experience of repeated agonistic interactions. The Cufflinks program was used to estimate the gene expression levels in FPKM units. The levels of the $\mathrm{Col}^{*}$ gene expression are presented in the control (left columns) and experimental mice (right columns) at the statistical significance ${ }^{*} P<0.05$; ${ }^{* \star} P<0.01 ;{ }^{* \star} P<0.001$. Additional statistics was shown in Supplement.

The Col1a2, Col3a1 and Col13a1 genes decreased their expression in the hypothalamus of the losers. According GeneCards database the Col1a2 and Col3a1 genes are associated with each other, and both participate in regulation of vascular system. Function of Col3a1 gene product is not known, however, it has been detected at low levels in all connective tissue-producing cells. Unlike most of the collagens, which are secreted into the ECM, Col3a1 gene protein has been localized to the plasma membrane, involved in cellmatrix and cell-cell adhesion interactions that are required for normal development. In the winners the Col1a2 gene was upregulated oppositely to the losers. It may be supposed that this gene may be responsible for specific expression of $\mathrm{Col}^{*}$ genes in the hypothalamus in every social group. This allows assuming differences in the state of the ECM in the hypothalamus of animals with alternative social experience. 
Little is known about the specific role of collagen genes in brain regions under functional uploads. It was previously shown that mRNA expression for the Col1a1 and Col3a1 genes was distinctly observed in pituitary glands of rats in cells located around capillaries in the gland and were supposed to be the main components of the ECM [Fujiwara et al. 2010]. Interestingly, in the hypothalamus of Djungarian hamsters, transcriptome analysis revealed upregulation of the Col18a1 and Col5a3 similar with our results, and increase of the Col17a1, Col20a1 and Col26a1 gene expression, which were specific for torpor in comparison with normothermic hamsters [Cubuk et al. 2017]. The preliminary hypothesis from this part of data may be the recognition of involvement $\mathrm{Col}^{*}$ genes into natural regulation, for example, of physiological adaptation under repeated stress in mice, winter torpor in hamsters, or CNS pathologies associated with collagens during neurodevelopment [Ali et al. 1998; Cheng et al. 2009; Lepelletier, et al. 2017].

In the midbrain raphe nuclei (Fig 2; Supplement, Table 1) expression of most genes therein was the lowest in comparison with other regions (<5.0 FPKM units). Nevertheless, similar with the hypothalamus, expression of the Col9a2 gene was upregulated in comparison with other genes. The Col6a2, Col15a1, Col24a1, and Col25a1 genes were downregulated and the Col6a3 and Col9a2 genes were upregulated similarly in both social groups. Specific alteration was upregulation of the Col6a1, Ccbe1 and Colq genes expression in the losers. Upregulation of the Plod2 and Plod3 genes and downregulation of the Plod1 gene expression were specific for the winners (Supplement, Table 1).

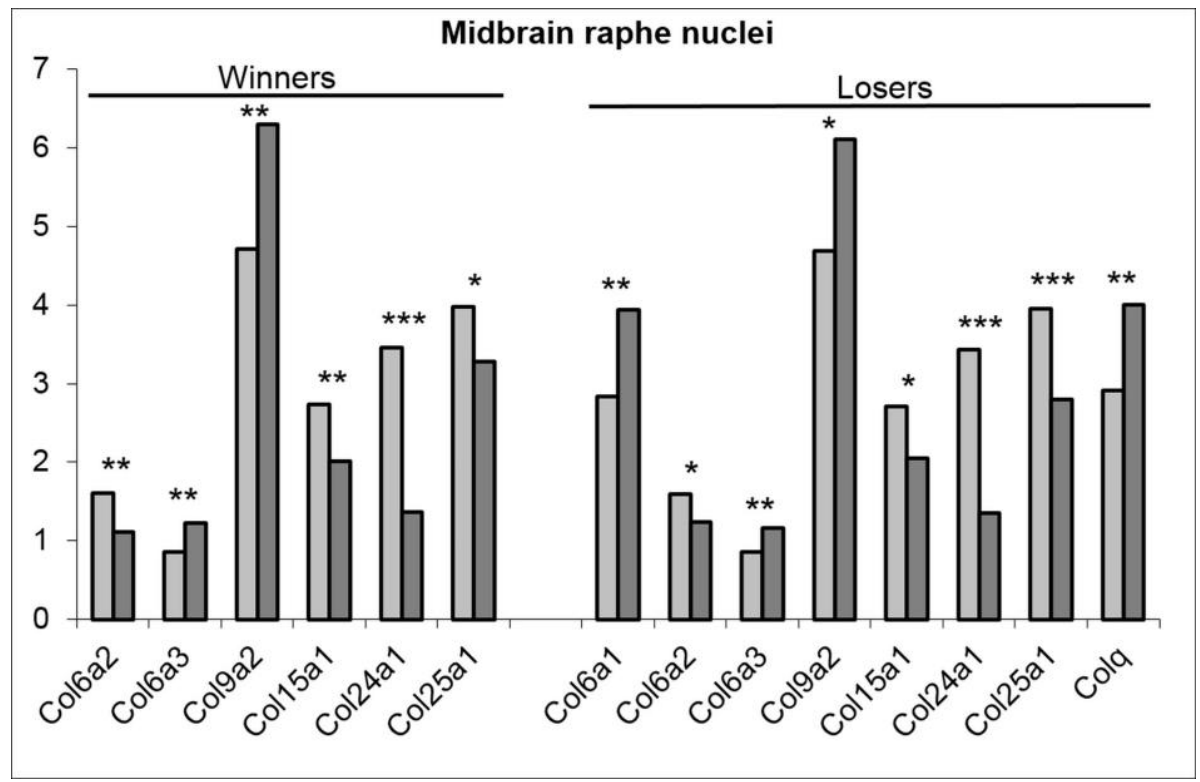

Figure 2. The differentially expressed collagen $\mathrm{Col}^{\star}$ family genes in the midbrain raphe nuclei of mice with agonistic interactions. The Cufflinks program was used to estimate the gene expression levels in FPKM units. The levels of the $\mathrm{Col}$ gene expression are presented in the control (left columns) and experimental mice (right columns) at the statistical significance ${ }^{*} P<0.05 ;{ }^{* \star} P<$ $0.01 ;{ }^{* \star} P<0.001$. Additional statistics was shown in Supplement.

The midbrain raphe nuclei contain the bodies of serotonergic neurons which are involved in the regulation of many physiological, behavioral, and emotional processes. Repeated experience of aggression and defeats is accompanied by the decrease of serotonergic activity [Kudryavtseva 2006; Avgustinovich et al. 2004], which is accompanied by decreased expression of serotonergic genes - Tph2, Maoa, Slc6a4, Htr's [Boyarskikh et al. 2013; Smagin et al. 2013; Kudryavtseva et al. 2017] in this brain region.

It has been shown, that stimulation of serotonin production may enhance the synthesis of some collagen proteins in human mesangial cells [Kasho et al., 1998]. On the other hands, 
bioRxiv preprint doi: https://doi.org/10.1101/276063; this version posted March 4, 2018. The copyright holder for this preprint (which was not certified by peer review) is the author/funder. All rights reserved. No reuse allowed without permission.

serotonin-dependent decrease in collagen mRNA was accompanied by decreased transcription serotonin, downregulating the gene for type I collagen and other the ECM proteins in myometrial cells [Passaretti et al. 1996]. Thus, we can suggest that decrease of some $\mathrm{Col}^{*}$ gene expression in the midbrain raphe nuclei of the winners and losers may be associated with decreased serotonergic activity.

In the VTA (Fig 3, Supplement, Table 1) all genes excepting the Col25a1 and Colgalt2 genes in the losers were downregulated in both groups with different social experience: the Col1a2, Col5a2, Col5a3, Col11a2, Col24a1, and Colq genes lowed their expression similarly in the winners and losers under agonistic interactions. The Col1a1, Col4a1, Col9a2, Col9a3, Col16a1, and Col23a1 genes specifically in the winners and the Col27a1 specifically in the losers were downregulated. Maximal overall expression manifested Col4a1, Col11a2, and Col16a1 genes in the winners and the Col11a2 gene in the losers.

Comparing the changes of $\mathrm{Col}^{*}$ gene expression in mice under agonistic interactions in the VTA and midbrain raphe nuclei, we noticed that only the Col24a1 gene similarly decreased expression in both brain regions in both social groups, while other genes which changed their expression were different. The identical genes, for example, the Col9a2 in the winners and the Col25a1 and Colq gene in the losers changed their expression oppositely in the midbrain raphe nuclei and VTA. That may indicate different processes in the ECM in brain regions. It's worth to notice that VTA and midbrain raphe nuclei contain pericarions of neurons. Serotonergic neurons are predominant in the midbrain raphe nuclei. The VTA contains 50-70\% dopaminergic neurons [Margolis et al. 2006; Nair-Roberts et al. 2008; Yamaguch et al. 2007], about 30\% of GABAergic neurons [Bourdy \& Barrot 2012] and 2-3\% of glutamatergic neurons [Margolis et al. 2006; Nair-Roberts et al. 2008]. We can assume that the type of collagen genes involved in the effects of agonistic interactions may be due to the difference in neurotransmitter systems involved in this process in various brain structures

In the hippocampus (Fig 3, Supplement, Table 1) expression of the Col1a1, Col1a2, Col3a1, Col5a1, Col5a2, Col6a1, Col6a2, Col9a2, Col12a1, Col13a1, Col18a1, Col23a1, Col27a1 genes were specifically upregulated in the losers and the Col6a3 gene was specifically upregulated in the winners. Expression of Col11a2 and Col8a2 genes was downregulated in the winners. Interestingly, expression of the Col6a4 gene was increased in the winners and was decreased in the losers. The Col16a1 gene changed the expression oppositely in these social groups. Again, similar with VTA, we can suppose different changes in the ECM in male mice with alternative social experience.

Interestingly, all of the ribosomal and mitoribosomal genes were upregulated in the winners in this region [Smagin et al. 2016b] and most of them were downregulated in the losers [Smagin et al. 2016a]. These dynamics in changes of expression of $R p^{*}$ genes we connected with different cell proliferation in this brain region. Repeated aggression has been shown to be accompanied by an increase in proliferation of neuronal progenitors and by production of new neurons in the dentate gyrus of the hippocampus [Smagin et al. 2015]. At the same time, other authors [Ferragud et al. 2010; Lagace et al. 2010; Van Bokhoven et al. 2011] have demonstrated the decreased cell proliferation in this brain region in defeated mice. It was suggested that the change in processes of neurogenesis is the consequence of ribosomal dysfunction developing under chronic positive or negative social experience in our experimental paradigm. Now we can suppose association between the decreased neurogenesis, the downregulation of ribosomal gene expression and the upregulation of $\mathrm{Col}^{*}$ genes expression in the losers and increased neurogenesis, upregulation of ribosomal gene expression and decreased $\mathrm{Col}^{*}$ gene expression in the hippocampus in the winners. However, we cannot exclude the possibility of the opposite relationship: changes in neurogenesis may influence the ribosomal and collagen functions. 

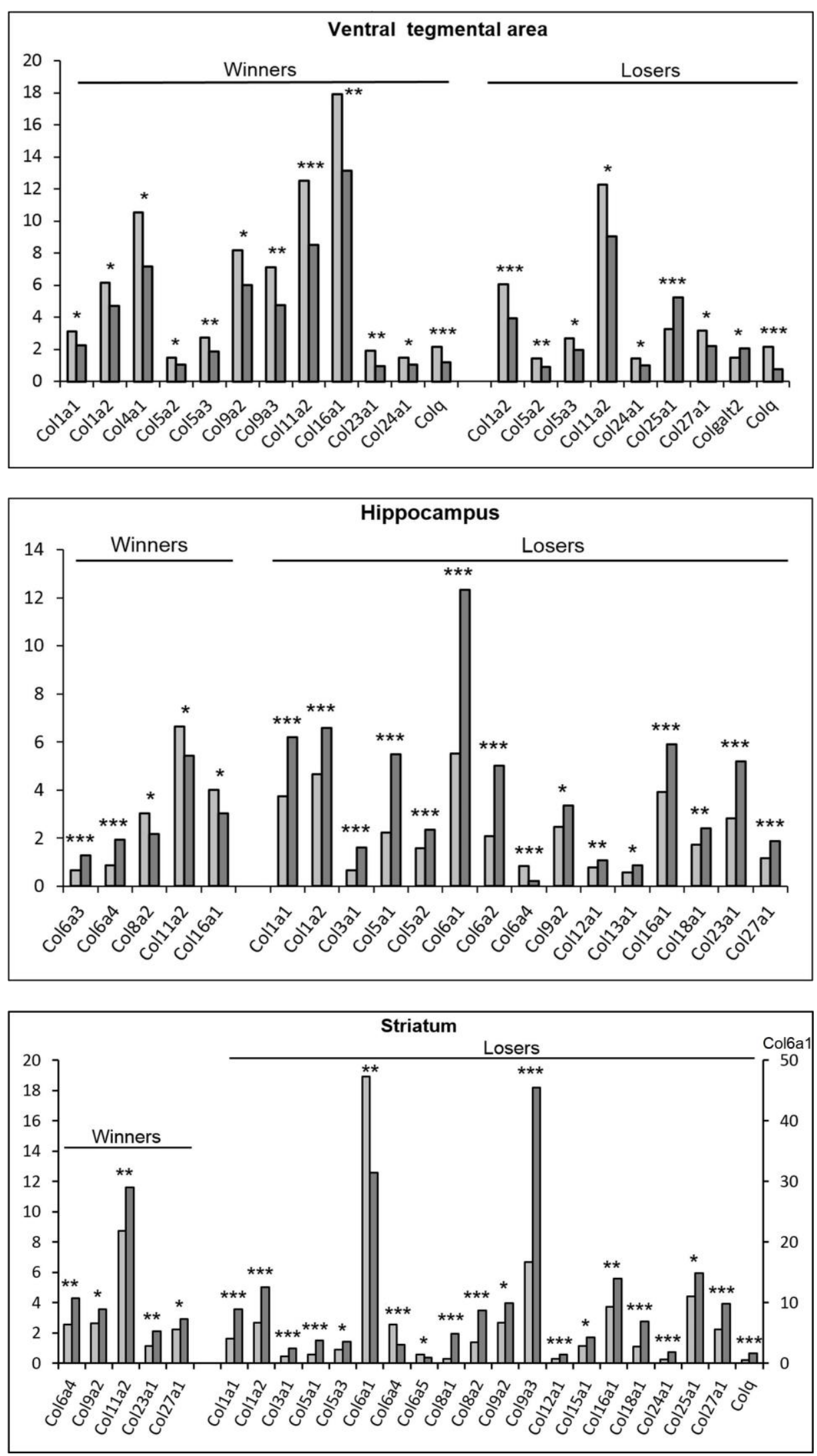

Figure 3. The differentially expressed collagen $\mathrm{Col}^{\star}$ family genes in the ventral tegmental area, hippocampus and striatum of mice with experience of repeated agonistic interactions. The Cufflinks program was used to estimate the gene expression levels in FPKM units. The levels of the $\mathrm{Col}$ gene expression are presented in the control (left columns) and experimental mice (right columns) at the statistical significance ${ }^{*} P<0.05 ;{ }^{* *} P<0.01 ;{ }^{* \star} P<0.001$. Additional statistics was shown in Supplement. 
bioRxiv preprint doi: https://doi.org/10.1101/276063; this version posted March 4, 2018. The copyright holder for this preprint (which was not certified by peer review) is the author/funder. All rights reserved. No reuse allowed without permission.

Association between neurogenesis and changes in $\mathrm{Col}^{*}$ gene expression is indirectly confirmed by experiments [Kakoi et al. 2012]: administration for 4 weeks orally of the lower molecular weight peptides derived from collagen enhanced the hippocampal neurogenesis and exerted anxiety-related behavior in adult mice: the density of proliferating cells in subgranular zone showed a 1.2-fold increase. Moreover, there is a growing volume of papers underlining that hippocampal functioning and axon outgrowth are tightly connected with collagen genes activation [Xia et al. 2013; Carletti et al. 2016]. Our preliminary analysis of brain specific genes underlined vesicular glutamate transporter S/c17a7 (VGLUT1) as strictly hippocampus specific highly expressed gene. In particular, we observed very intense expression rate of vesicle transporting gene S/c17a7 specifically in the hippocampus samples of our mice (Figure 1). This gene was shown to be implicated in neuroendocrine response upon chronic stress experience [Myers et al. 2017]. Some data suggest a functional role of SLC17A7 in the hippocampal synaptic plasticity [Balschun et al. 2010; Li et al. 2011; Bogen et al. 2009], though there is no direct evidence of its activity and synapse plasticity [Fung et al., 2011]. The expression pattern of S/c17a7 gene in our data was highly correlated with at least three collagen genes: Col19a1 ( $r=0.88$; $d f=43 ; P<1 \mathrm{E}-6)$, Col5a1 $(r$ $=0.77 ; d f=43 ; P<1 \mathrm{E}-5)$, Col4a1 $(r=0.4 ; d f=43)$. Notably, all of these proteins express specifically in neuronal cells [Zhang et al. 2014]. It underscores the ultimate importance of collagen families of the reported previously axon outgrowth and synapse activation in hippocampus specifically upon the stress experience [Hayashi, 2015]. In particular, the neurons will grow their neuritis along the collagen matrix since they maintain receptors on their plasma membrane adhesive to the collagen. The implications of collagen deviated expression may signal on specific events in synapse and axon ramifications/functions. One of other points worth mentioning about neuron-specific collagen activities is that the above mentioned Col5a1 expression rate is manifested as hippocampus specific, at the same time highly elevated in the hippocampus of depressive mice in our data. This elevation is highly significant and consistent. We should note that such consistency in a group - specific expression pattern is quite rarely observed in ours and other data.

In the striatum (Fig 3, Supplement, Table 1) the Col6a4, Col9a2, and Col27a1 genes were upregulated in both social groups. The upregulation of gene expression specific for the winners was shown for the Col11a2 and Col23a1 genes, and specific for losers - for the Col1a1, Col1a2, Col3a1, Col5a1, Col5a3, Col8a1, Col8a2, Col9a3, Col12a1, Col15a1, Col16a1, Col18a1, Col24a1, Col25a1, Colq, Pcolce2, Pcolce, Plod1, and Cthrc1 genes. Decreased expression was revealed for the Col6a1, Col6a4 and Col6a5 genes in the losers. Similarly with the hippocampus the Col6a4 gene was upregulated in the winners and downregulated in the losers. Highest expression was shown for the Col6a1 gene in the losers.

The striatum is responsible for the modulation of movement pathways and is potentially involved in a variety of other cognitive processes responsible for regulation of motor activity and stereotypic behaviors. The winners demonstrate hyperactivity and enhanced locomotion in behavioral tests and stereotypical behaviors, etc. [Kudryavtseva 2006; Kudryavtseva et al. 2014; Vishnivetskaya et al. 2013]. In the losers with low locomotor and exploratory activity, helplessness, and immobility behavior in any situation, the total number of differentially expressed genes was 4 times more than in the winners, and the majority of these genes in this brain region were upregulated [Smagin et al. 2017]. In spite of differences in the locomotor behavior in the winners and losers, the majority of differentially expressed genes were upregulated in both social groups.

\section{Principal components analysis (PC) of $\mathrm{Col}^{*}$ gene expression in the RNA-Seq data}

To assess the degree of brain region-specific expression of genes of interest, we performed a Principal Components analysis based on the co-variation of 49 genes using the expression profiles of 45 samples, which comprised RNA-Seq FPKM data for 5 brain regions of 9 mice. Ovals correspond to brain regions. We identified compact clustering of the hypothalamus, 
striatum and hippocampus samples based on gene expression profiles (Fig 4, encircled), whereas the midbrain raphe nuclei and ventral tegmental area were merged.

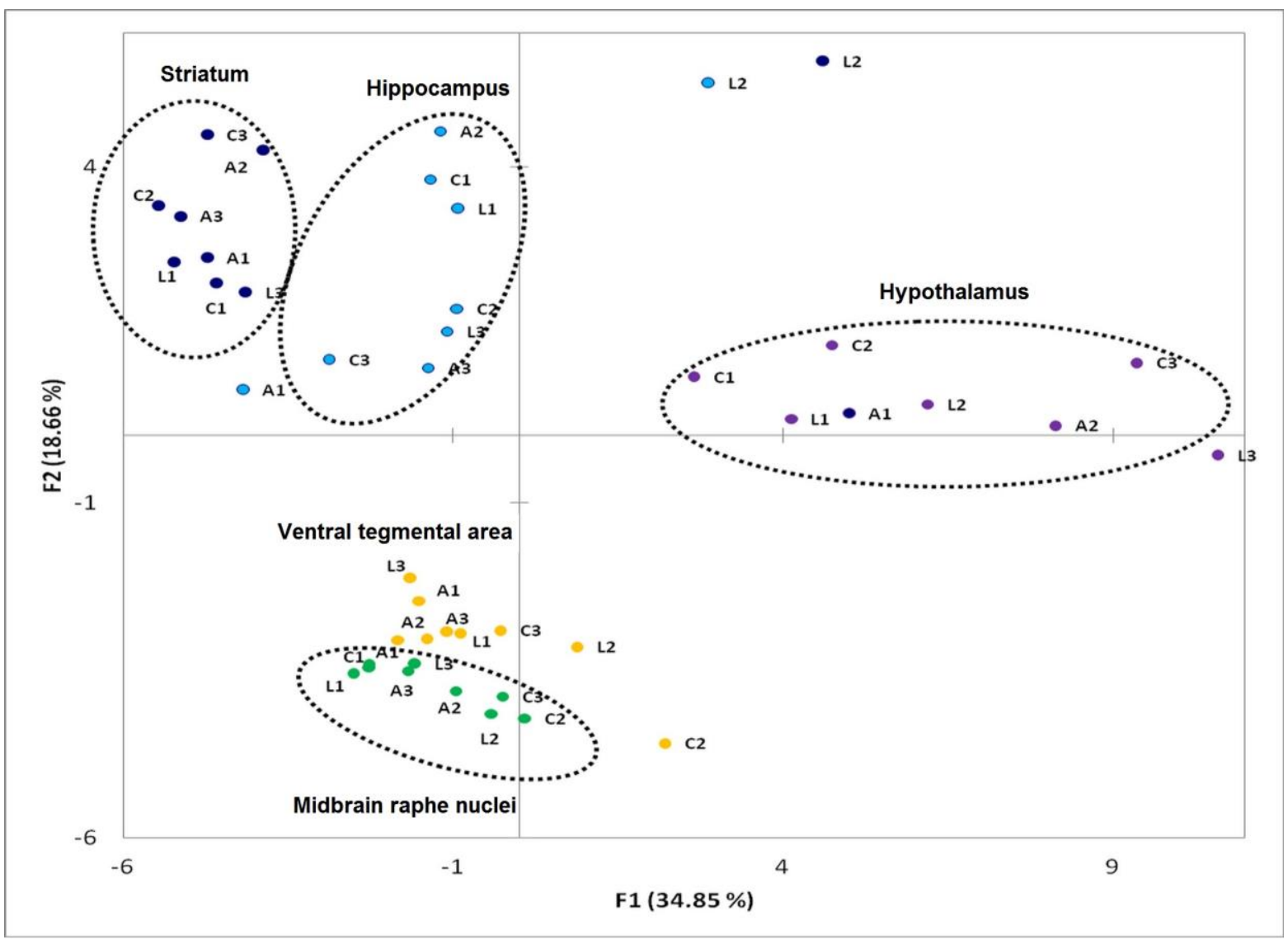

Figure 4. Principal component analysis plot based on co variation of $49 \mathrm{Col}^{*}$ family genes using the expression profiles of 45 samples, which comprised RNA-Seq FPKM data for 5 brain regions of 9 mice. Ovals correspond to brain regions. C1, C2, C3 - control; A1, A2, A3 - aggressive mice; L1, L2, L3 - defeated mice, losers. Distinct clustering of three brain regions occurred, whereas the midbrain raphe nuclei and ventral tegmental area were not distinct.

\section{Agglomerative hierarchical clustering $(\mathrm{AHC})$ of $\mathrm{Col}^{*}$ genes coding transcripts and identification of outliers}

We applied AHC to the initial sample of 49 genes, based on their expression profiles (Fig. 5) presents the dendrogram of gene clustering. The similarity ordinate corresponds to the Pearson correlation coefficient $(\mathrm{df}=44)$. An $\mathrm{AHC}$ analysis elucidates closely correlated genes, which thus strengthens the confidence of concordant differential expressions of a gene pair based on their highly correlated expression profiles across 45 samples. Thus, we reaffirm the significant differential expression given correlated pairs of genes and independent tests using the Cufflinks program. The overlapping or specific $\mathrm{Col}^{*}$ genes in different brain areas of the winners and losers are presented in Supplement, Table 1.

\section{General discussion}

We should underline principal points in dealing with collagen genes. We found the effect for brain regions in the winners and losers, and we were able to see consistent elevations and downturns of expression rate for particular groups of collagen proteins across brain regions that were elucidated by PC analysis underlining their brain region specific expression profile. 


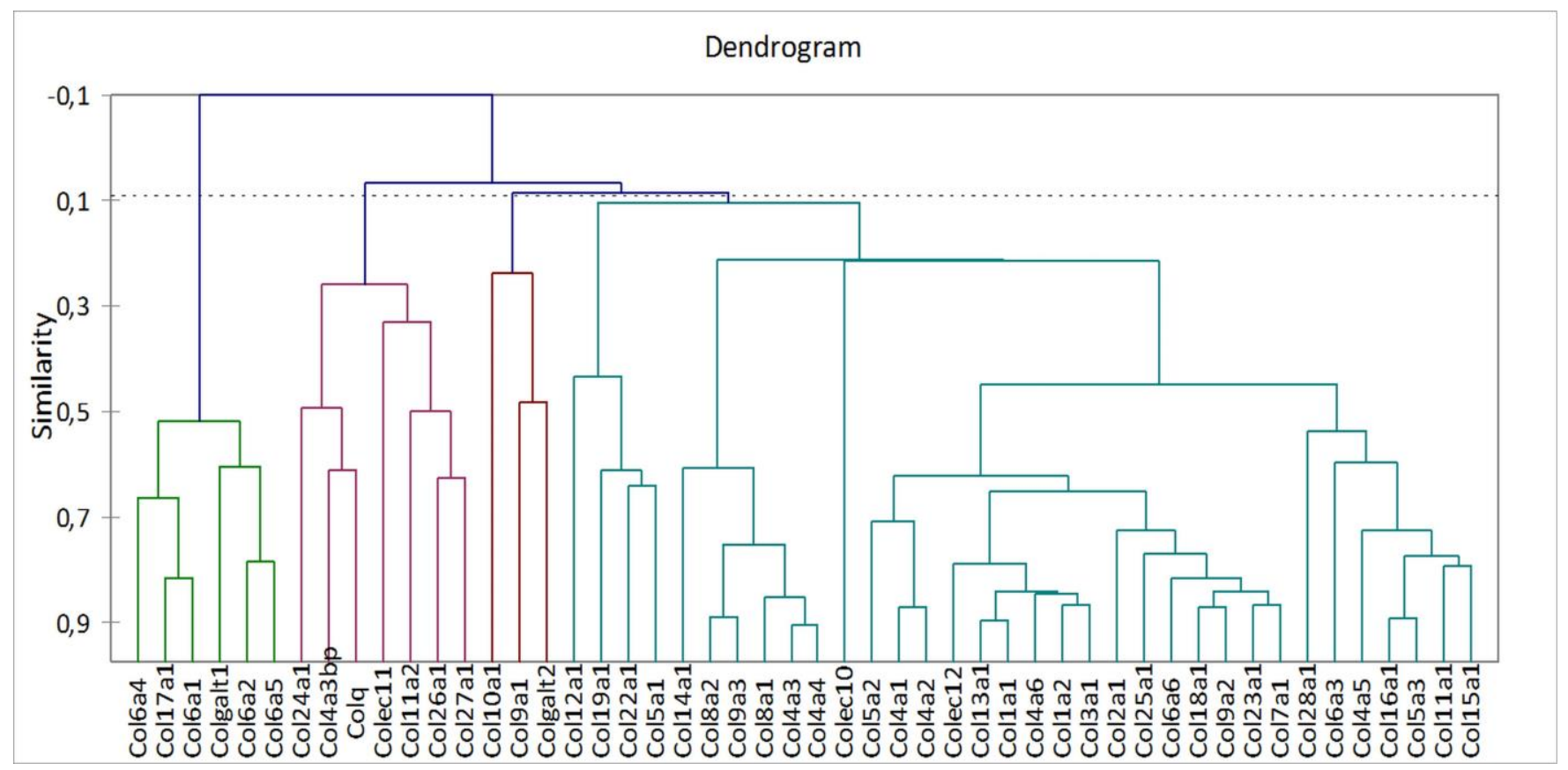

Figure 5. Agglomerative hierarchical clustering of $\mathrm{Col}^{*}$ coding transcripts and identification of outliers. We applied agglomerative hierarchical clustering to the initial sample of 49 genes across 45 samples, which comprised RNA-Seq FPKM data for 5 brain regions of 9 mice based on their expression profiles. Figure presents the dendrogram of gene clustering. The similarity ordinate corresponds to the Pearson correlation coefficient $(\mathrm{df}=44)$.

In the hypothalamus, striatum and hippocampus the most of $\mathrm{Col}^{*}$ genes were upregulated, and the amount of differentially expressed genes in the striatum and hippocampus was significantly more in the losers than in the winners. In the midbrain raphe nuclei and VTA expression of the most of $\mathrm{Col}^{*}$ genes were downregulated. In has been shown that the direction of changes in expression of some Col* genes depended also on social experience of mice: some genes changed their expression specific for the winners and for the losers.

We can assume the dysfunction of the ECM due to aberrant $\mathrm{Col}^{*}$ gene expression. We can suppose also that changed neurotransmitter activity involved in the regulation of pathological states primarily creates the conditions for development of aberrant functioning of the ECM which, as consequence, produces changes in works of many metabolic genes including ribosomal and mitoribosomal genes shown earlier for brain regions [Smagin et al. 2016a; Smagin et al. 2016b].

It was proposed [Kerrisk 2014; Bonneh-Barkay \& Wiley 2009] that collagens can serve many functions, such as mediating cell adhesion, segregating tissues from one another, and regulating intercellular connection, transmitting signals to cell surface adhesion receptors, and participating in the regulation of synaptic plasticity. Changes in physiological conditions can trigger the rapid and local growth factor-mediated activation of cellular functions without additional synthesis. The stiffness and elasticity of the ECM, as supposed, have important implications in cell migration, gene expression, and differentiation [Engler et al. 2006; Frantz et al. 2010; Wang et al. 2007]. The precise expression pattern of collagen genes depends on a balance of positive and negative transcription factors, proteins that control the synthesis of mRNA from the specific gene [Okazaki \& Sandell 2004]. Authors suppose that during development or the disease, the specific genes must be expressed in order to make or repair appropriate ECM. In any case, there are dynamic interrelations between the ECM influences on gene expression via transmembrane proteins as was earlier supposed by previous hypothesis [Slavkin 1982; Bissell \& Barcellos-Hoff 1987]. In turn, changes in expression of numerous genes may impact cell interactions with other cells, creating novel biogenic environment, which may be reason of aberrant $\mathrm{Col}^{*}$ gene expression. 
The majority of collagen disorders are associated with neurological abnormalities including seizures and myoclonus, psychomotor retardation, spasticity, motor neuron disease, weakness, chronic fatigue, and endocrine abnormalities etc. Aggressive and defeated mice have also been shown to demonstrate disturbances in motor activity and neurological symptoms [Kudryavtseva 2006; Kudryavtseva et al. 2014; Vishnivetskaya et al. 2013; Smagin et al. 2018]. We suggest that collagen abnormalities in male mice with alternative social experience can be considered as development of "functional collagenopathy" as opposed to a collagenopathy that is induced by mutations accompanied by alterations in the structure or function of collagen components.

At this stage of our research, it is impossible to elucidate the detailed succession of neurochemical and molecular events which occur as a result of changes in brain regulation under repeated agonistic interactions in male mice. However, it is clear that this process is starting with a change in social behaviors and, at a certain stage, launches a cascade of systemic changes in the whole brain, specific regions, metabolism, neurons, and the neurotransmitter systems, which leads to a change in the expression of numerous genes. We can assume that the aberrant expression of genes is a consequence but not a reason of different psychopathologies. The next stage of our work will be to find the key, major genes that run the entire chain of events from the changes in social behaviors to changes in the gene expression.

\section{Acknowledgments}

This work was funded by Russian Science Foundation, grant no. 14-15-00063.

\section{References}

Ali, S.A., Pappas, I.S. \& Parnavelas, J.G. (1998) Collagen type IV promotes the differentiation of neuronal progenitors and inhibits astroglial differentiation in cortical cell cultures. Brain Res Dev Brain Res 110 (1), 31-38.

APA. Diagnostic and statistical manual of mental disorders. 5th ed. Washington, DC: American Psychiatric Publishing, 2013.

Avgustinovich, D.F., Alekseyenko, O.V., Bakshtanovskaia, I.V., Koriakina, L.A., Lipina, T.V., Tenditnik, M.V., Bondar', N.P., Kovalenko, I.L. \& Kudriavtseva, N.N. (2004) Dynamic changes of brain serotonergic and dopaminergic activities during development of anxious depression: Experimental Study. Usp Fiziol Nauk 35(4), 19-40 (Russian).

Berton, O., McClung, C.A., Dileone, R.J., Krishnan, V., Renthal, W., Russo, S.J., Graham, D., Tsankova, N.M., Bolanos, C.A., Rios, M., Monteggia, L.M., Self, D.W. \& Nestler, E.J. (2006) Essential role of BDNF in the mesolimbic dopamine pathway in social defeat stress. Science 311, 864-868

Bissell, M.J. \& Barcellos-Hoff, M.H. (1987) The influence of extracellular matrix on gene expression: is structure the message? J Cell Sci Suppl 8, 327-343.

Babenko, V.N., Smagin, D.A., \& Kudryavtseva, N.N. (2017) RNA-Seq Mouse Brain Regions expression Data Analysis: Focus on ApoE Functional Network. J Integ. Bioinformatics. 2017; 20170024

Bogen, I.L., Jensen, V., Hvalby, O., Walaas, S.I. (2009) Synapsin-dependent development of glutamatergic synaptic vesicles and presynaptic plasticity in postnatal mouse brain. Neuroscience 158(1):231-241.

Balschun, D., Moechars, D., Callaerts-Vegh, Z., Vermaercke, B., Van Acker, N., Andries,L,, D'Hooge, R. (2010) Vesicular glutamate transporter VGLUT1 has a role in hippocampal long-term potentiation and spatial reversal learning. Cereb Cortex 20(3]:684-693.

Bondar, N.P., Boyarskikh, U.A., Kovalenko, I.L., Filipenko, M.L. \& Kudryavtseva, N.N. (2009) Molecular implications of repeated aggression: Th, Dat1, Snca and Bdnf gene expression in the ventral tegmental area of victorious male mice. PLoS One 4 (1):e4190. 
Bondar, N.P., Kovalenko, I.L., Avgustinovich, D.F., Smagin, D.A., \& Kudryavtseva, N.N. (2009) Anhedonia in the shadow of chronic social defeat stress, or When the experimental context matters. Open Behav Sci J 3, 17-27.

Bonneh-Barkay, D. \& Wiley, C.A. (2009) Brain extracellular matrix in neurodegeneration. Brain Pathol; 19(4), 573-585.

Bourdy, R. \& Barrot, M. (2012) A new control center for dopaminergic systems: pulling the VTA by the tail. Trends Neurosci 35 (11), 681-690.

Boyarskikh, U.A., Bondar, N.P., Filipenko, M.L. \& Kudryavtseva, N.N. (2013) Downregulation of serotonergic genes expression in the raphe nuclei of midbrain under chronic social defeat stress in male mice. Mol Neurobiol 48(1), 13-21.

Carletti F, Sardo P, Gambino G, Liu XA, Ferraro G, \& Rizzo V. (2016) Hippocampal hyperexcitability is modulated by microtubule-active agent: Evidence from In vivo and in vitro epilepsy models in the rat. Front Cell Neurosci. Feb 9; 10:29.

Cescon, M., Gattazzo, F., Chen, P. \& Bonaldo, P. (2015) Collagen VI at a glance. J. Cell Sci 128, 3525-3531.

Cheng, J.S., Dubal, D.B., Kim, D.H., Legleiter, J., Cheng, I.H., Yu, G.Q., Tesseur, I., Wyss-Coray, T., Bonaldo, P., \& Mucke, L. (2009) Collagen VI protects neurons against Abeta toxicity. Nat Neurosci 12(2), 119-121.

Chernousov, M,A., Rothblum, K., Stahl, R.C., Evans, A., Prentiss, L., \& Carey, D.J. (2006) Glypican-1 and alpha4(V) collagen are required for Schwann cell myelination. J. Neurosci 26, 508-517.

Claudepierre, T., Manglapus, M.K., Marengi, N., Radner, S., Champliaud, M.F., Tasanen, K., Bruckner-Tuderman. L., Hunter, D.D., \& Brunken, W.J. (2005) Collagen XVII and BPAG1 expression in the retina: evidence for an anchoring complex in the central nervous system. J Comp Neurol. 487(2), 190-203.

Cubuk, C., Kemmling, J., Fabrizius, A. \& Herwig, A. (2017) Transcriptome analysis of hypothalamic gene expression during daily torpor in Djungarian hamsters (Phodopus sungorus). Front Neurosci $11,122$.

Engler, A.J., Sen, S., Sweeney, H.L. \& Discher, D.E. (2006) Matrix elasticity directs stem cell lineage specification. Cell 126(4), 677-689.

Ferragud, A., Haro, A., Sylvain, A., Velázquez-Sánchez, C., Hernández-Rabaza, V. \& Canales, J.J. (2010) Enhanced habit-based learning and decreased neurogenesis in the adult hippocampus in a murine model of chronic social stress. Behav Brain Res 210, 1, 134-139.

Filipenko, M.L., Alekseyenko, O.V., Beilina, A.G., Kamynina, T.P. \& Kudryavtseva, N.N. (2001) Increase of tyrosine hydroxylase and dopamine transporter mRNA levels in ventral tegmental area of male mice under influence of repeated aggression experience. Brain Res, Mol Brain Res 96, 7781.

Forsell, C., Bjork, B.F., Lilius, L., Axelman, K., Fabre, S.F., Fratiglioni, L., Winblad, B., \& Graff, C. (2010) Genetic association to the amyloid plaque associated protein gene COL25A1 in Alzheimer's disease. Neurobiol Aging 31(3), 409-415.

Fox, M.A. (2008) Novel roles for collagens in wiring the vertebrate nervous system. Curr Opin Cell Biol 20 (5), 508-513.

Fox, M.A., Sanes, J.R., Borza, D.B., Eswarakumar, V.P., Fässler, R., Hudson, B.G., John, S.W., Ninomiya, Y., Pedchenko, V., Pfaff, S.L., Rheault, M.N., Sado, Y., Segal, Y., Werle, M.J., \& Umemori, H. (2007) Distinct target-derived signals organize formation, maturation, and maintenance of motor nerve terminals. Cell 129(1), 179-193.

Frantz, C., Stewart, K.M. \& Weaver, V.M. (2010) The extracellular matrix at a glance. J Cell Sci 123, 4195-4200.

Fujiwara, K., Jindatip, D., Kikuchi, M. \& Yashiro, T. (2010) In situ hybridization reveals that type I and III collagens are produced by pericytes in the anterior pituitary gland of rats. Cell Tissue Res 342(3), 491-495. 
Fung, S.J., Sivagnanasundaram, S., Weickert, C.S. (2011) Lack of change in markers of presynaptic terminal abundance alongside subtle reductions in markers of presynaptic terminal plasticity in prefrontal cortex of schizophrenia patients. Biol Psychiatry. 69(1):71-79.

Galyamina, A.G., Kovalenko, I.L., Smagin, D.A. \& Kudryavtseva, N.N. (2017) Interaction of depression and anxiety in the development of mixed anxiety/depression disorder. Experimental studies of the mechanisms of comorbidity (review). Neurosci Behav Physiol 47(6), DOI 10.1007/s11055-017-04583.

Galyamina, A.G., Kovalenko, I.L., Smagin, D.A. \& Kudryavtseva, N.N. (2017) Altered expression of neurotransmitters genes in the ventral tegmental area of depressive male mice: RNA-Seq. Zh Vyssh Nerv Deiat Im I P Pavlova 1, 113-118.

Gordon, M.K. \& Hahn, R.A. (2010) Collagens. Cell Tissue Res. 339, 247-257.

Grässel, S., \& Bauer, R.J. (2013) Collagen XVI in health and disease. Matrix Bio/ 32(2), 64-73.

Hayashi, T. Conversion of psychological stress into cellular stress response: roles of the sigma-1 receptor in the process. (2015) Psychiatry Clin Neurosci (2015) 69 (4):179-191.

Hashimoto, T., Wakabayashi, T., Watanabe, A., Kowa, H., Hosoda, R., Nakamura, A., Kanazawa, I., Arai, T., Takio, K., Mann, D.M., \& Iwatsubo, T. (2002) CLAC: a novel Alzheimer amyloid plaque component derived from a transmembrane precursor, CLAC-P/collagen type XXV. EMBO J 21(7), 1524-1534.

Heffron, D.S., Landreth, G.E., Samuels, I.S., \& Mandell, J,W. (2009) Brain-specific deletion of extracellular signal-regulated kinase 2 mitogen-activated protein kinase leads to aberrant cortical collagen deposition. Am J Pathol 175(6), 2586-2599.

Hollis, F., Wang, H., Dietz, D., Gunjan, A. \& Kabbaj, M. (2010) The effects of repeated social defeat on long-term depressive-like behavior and short-term histone modifications in the hippocampus in male Sprague-Dawley rats. Psychopharmacology 211(1), 69-77.

Hubert, T., Grimal, S., Carroll, P., \& Fichard-Carroll, A. (2009) Collagens in the developing and diseased nervous system. Cell Mol Life Sci 66(7), 1223-1238.

Ibrahim, M.K., Hassanein, N.M.A. \& Ahmed, H.M.S. (2016) Psychopharmacological assessment of the sensory contact model for mania. J. Global Biosci 5(3), 3725-3741.

Kadakkuzha, B.M., Liu, X.A., McCrate, J., Shankar, G., Rizzo, V., Afinogenova, A., Young, B., Fallahi, M., Carvalloza, A.C., Raveendra, B., Puthanveettil, S.V. (2015) Transcriptome analyses of adult mouse brain reveal enrichment of IncRNAs in specific brain regions and neuronal populations. Front Cell Neurosci 9 (63), doi: 10.3389/fncel.2015.00063

Kadler, K.E., Baldock, C., Bella, J., \& Boot-Handford, R.P. (2007) Collagens at a glance. J Cell Sci 120(Pt 12), 1955-1958.

Kakoi, C., Udo, H., Matsukawa, T. \& Ohnuki, K. (2012) Collagen peptides enhance hippocampal neurogenesis and reduce anxiety related behavior in mice. Biomed Res 33(5), 273-279.

Kasho, M., Sakai, M., Sasahara, T., Anami, Y., Matsumura, T., Takemura, T., Matsuda, H., Kobori, S. \& Shichiri, M. (1998) Serotonin enhances the production of type IV collagen by human mesangial cells Kidney Int 54(4), 1083-1092.

Kenworthy, C.A., Sengupta, A., Luz, S.M., Ver Hoeve, E.S., Meda, K., Bhatnagar, S. \& Abel, T. (2014) Social defeat induces changes in histone acetylation and expression of histone modifying enzymes in the ventral hippocampus, prefrontal cortex, and dorsal raphe nucleus. Neuroscience 264, 88-98.

Kerrisk, M.E., Cingolani, L.A. \& Koleske, A.J. (2014) ECM receptors in neuronal structure, synaptic plasticity, and behavior. Prog Brain Res 214, 101-131.

Kovalenko, I.L., Smagin, D.A., Galyamina, A.G., Orlov, Y.L. \& Kudryavtseva, N.N. (2016) Changes in the expression of dopaminergic genes in brain structures of male mice exposed to chronic social defeat stress: an RNA-seq study. Mol Biol (Mosk) 50(1), 184-187.

Kudryavtseva, N.N. (1991) The sensory contact model for the study of aggressive and submissive behaviors in male mice. Aggress Behav 17(5), 285-291. 
Kudryavtseva, N.N. (2006) Psychopathology of repeated aggression: a neurobiological aspect. In: Morgan, J.P. (Ed.), Perspectives on the Psychology of Aggression. NOVA Science Publishers, Inc. 35-64. Review.

Kudryavtseva, N.N. \& Avgustinovich, D.F. (1998) Behavioral and physiological markers of experimental depression induced by social conflicts. Aggress Behav 24, 271-286.

Kudryavtseva, N.N., Bakshtanovskaya, I.V. \& Koryakina, L.A. (1991) Social model of depression in mice of C57BL/6J strain. Pharmacol Biochem Behav 38(2), 315-320.

Kudryavtseva, N.N., Bondar, N.P. \& Avgustinovich, D.F. (2002) Association between experience of aggression and anxiety in male mice. Behav Brain Res 133(1), 83-93

Kudryavtseva, N.N., Filipenko, M.L., Bakshtanovskaya, I.V., Avgustinovich, D.F., Alekseenko, O.V. \& Beilina, A.G. (2004) Changes in the expression of monoaminergic genes under the influence of repeated experience of agonistic interactions: From behavior to gene. Rus J Genetics 40(6), 590604.

Kudryavtseva, N.N., Smagin, D.A., Kovalenko, I.L., Galyamina, A.G., Vishnivetskaya, G.B., Babenko, V.N. \& Orlov Y.L. (2017) Serotonergic genes in the development of anxiety/depression-like state and pathology of aggressive behavior in male mice: RNA-Seq data. Mol Biol (Mosk) 519(2), 251-262.

Kudryavtseva, N.N., Smagin, D.A., Kovalenko I.L. \& Vishnivetskaya, G.B. (2014) Repeated positive fighting experience in male inbred mice. Nat Protoc 9 (11), 2705-2717.

Lagace, D.C., Donovan, M.H., DeCarolis, N.A., Farnbauch, L.A., Malhotra, S., Berton, O., Nestler, E.J., Krishnan, V. \& Eisch, A.J. (2010) Adult hippocampal neurogenesis is functionally important for stress-induced social avoidance. Proc Natl Acad Sci USA 107(9), 4436-4441.

Lepelletier, F.X., Mann, D.M., Robinson, A.C., Pinteaux, E., \& Boutin, H. (2017) Early changes in extracellular matrix in Alzheimer's disease. Neuropathol Appl Neurobiol 43(2), 167-182.

Li, E., Kim, D.H., Cai, M., Lee, S., Kim, Y., Lim, E., Hoon Ryu, J., Unterman, T.G., Park, S. (2001) Hippocampus-dependent spatial learning and memory are impaired in growth hormone-deficient spontaneous dwarf rats. Endocr J 58(4), 257-267.

Li, X.H., Chen, J.X., Yue, G.X., Liu, Y.Y., Zhao, X., Guo, X.L., Liu, Q., Jiang, Y.M. \& Bai, M.H. (2013) Gene expression profile of the hippocampus of rats subjected to chronic immobilization stress. PLoS One 8(3):e57621.

Margolis, E.B., Lock, H., Hjelmstad, G.O. \& Fields, H.L. (2006) The ventral tegmental area revisited: Is there an electrophysiological marker for dopaminergic neurons? J Physiol. 577 (3), 907-924.

Myers, B., McKlveen, J.M., Morano, R., Ulrich-Lai, Y.M., Solomon, M.B., Wilson, S.P., Herman, J.P. (2017) Vesicular glutamate transporter 1 knockdown in infralimbic prefrontal cortex augments neuroendocrine responses to chronic stress in male rats. Endocrinology. 2017. 158(10), 3579-3591.

Myllyharju, J. \& Kivirikko, K.I. (2004) Collagens, modifying enzymes and their mutations in humans, flies and worms. Trends Genet 20, 33-43.

Nair-Roberts, R.G., Chatelain-Badie, S.D., Benson, E., White-Cooper, H., Bolam, J.P. \& Ungless, M.A. (2008) Stereological estimates of dopaminergic, GABAergic and glutamatergic neurons in the ventral tegmental area, substantia nigra and retrorubral field in the rat. Neuroscience 152, 10241031.

Okazaki, K. \& Sandell, L.J. (2004) Extracellular matrix gene regulation. Clin Orthop Relat Res (427 Suppl), S123-128.

Passaretti, T.V., Wilcox, B.D., \& Jeffrey, J.J. (1996) Serotonin regulation of gene expression in uterine extracellular matrix: reciprocal effects on collagens and collagenase. Mol Cell Endocrinol 120(2), 125-132.

Ricard-Blum S. (2011) The collagen family. Cold Spring Harb Perspect Biol. 1, 3(1):a004978.

Schneider, V.A., \& Granato, M. (2006) The myotomal diwanka (Ih3) glycosyltransferase and type XVIII collagen are critical for motor growth cone migration. Neuron 50(5), 683-695. 
Seppänen, A., Autio-Harmainen, H., Alafuzoff, I., Sarkioja, T., Veijola, J., Hurskainen, T., BrucknerTuderman, L., Tasanen, K., \& Majamaa, K. (2006) Collagen XVII is expressed in human CNS neurons. Matrix Biol 25(3), 185-188.

Seppänen, A., Suuronen, T., Hofmann, S.C., Majamaa, K., \& Alafuzoff, I. (2007) Distribution of collagen XVII in the human brain. Brain Res 1158, 50-56.

Sertie, A.L., Sossi, V., Camargo, A.A., Zatz, M., Brahe, C., \& Passos-Bueno, M.R. (2000) Collagen $\mathrm{XVIII}$, containing an endogenous inhibitor of angiogenesis and tumor growth, plays a critical role in the maintenance of retinal structure and in neural tube closure (Knobloch syndrome). Hum Mol Genet 9(13), 2051-2058.

Slavkin, H. (1982) Combinatorial process for extracellular matrix influences on gene expression: A hypothesis J Craniofac Genet Dev Biol 2(2), 179-189.

Smagin, D.A., Boyarskikh, U.A., Bondar, N.P., Filipenko, M.L. \& Kudryavtseva, N.N. (2013) Reduction of serotonergic gene expression in the midbrain raphe nuclei under positive fighting experience. Adv Biosci Biotech 4, 10B, 36-44.

Smagin, D.A., Galyamina, A.G., Kovalenko, I.L., Babenko, V.N., Tamkovich, N.V., Borisov, S.A., Tolstikova, T.G. \& Kudryavtseva, N.N. (2018) Altered expression of neurotransmitter genes in the dorsal striatum of male mice with psychomotor disturbances. Zh Vyssh Nerv Deiat Im I P Pavlova 2 (in press).

Smagin, D.A., Kovalenko, I.L., Galyamina, A.G., Bragin, A.O., Orlov, Yu.L. \& Kudryavtseva, N.N. (2016a) Dysfunction in ribosomal gene expression in the hypothalamus and hippocampus following chronic social defeat stress in male mice as revealed by RNA-seq. Neur. Plast ID 3289187, 6.

Smagin, D.A., Kovalenko, I.L., Galyamina, A.G., Orlov, Yu.L., Babenko, V.N. \& Kudryavtseva, N.N. (2016b) Heterogeneity of brain ribosomal gene expression following repeated experience of aggression in male mice as revealed by RNA-Seq. Mol Neurobiol doi:10.1007/s12035-016-0327-z

Smagin, D.A., Park, J.-H., Michurina, T.V., Peunova, N., Glass, Z., Sayed, K., Bondar, N.P., Kovalenko, I.L., Kudryavtseva, N.N. \& Enikolopov, G. (2015) Altered hippocampal neurogenesis and amygdalar neuronal activity in adult mice with repeated experience of aggression. Front Neurosci 9, 443. doi: 10.3389/fnins.2015.00443.

Sund, M., Vaisanen, T., Kaukinen, S., Ilves, M., Tu, H., Autio-Harmainen, H., \& Rauvala, H., Pihlajaniemi, T. (2001) Distinct expression of type XIII collagen in neuronal structures and other tissues during mouse development. Matrix Biol 20(4), 215-231.

Tong, Y., Xu, Y., Scearce-Levie, K., Ptácek, L.J. \& Fu, Y.H. (2010) COL25A1 triggers and promotes Alzheimer's disease-like pathology in vivo. Neurogenetics 11(1), 41-52.

Trapnell, C., Hendrickson, D.G., Sauvageau, M., Goff, L., Rinn, J.L. \& Pachter, L. (2013) Differential analysis of gene regulation at transcript resolution with RNA-seq. Nat Biotechnol 31(1), 46-53.

Van Bokhoven, P., Oomen, C.A., Hoogendijk, W.J., Smit, A.B., Lucassen, P.J. \& Spijker, S. (2011) Reduction in hippocampal neurogenesis after social defeat is long-lasting and responsive to late antidepressant treatment. Eur J Neurosci 33(10), 1833-1840.

Vishnivetskaya, G.B., Avgustinovich, D.F. \& Kudryavtseva, N.N. (2013) Development of movement disorders in DBA/2J male mice under repeated experience of aggression. Zh Vyssh Nerv Deiat Im I P Pavlova 63(2), 235-245.

Wang, J.H., Thampatty, B.P., Lin, J.S. \& Im, H.J. (2007) Mechanoregulation of gene expression in fibroblasts. Gene 391, 1-15.

Xia, C., Nguyen, M., Garrison, A.K., Zhao, Z., Wang, Z., Sutherland, C., Ma, L. (2013) CNP/cGMP signaling regulates axon branching and growth by modulating microtubulepolymerization. Dev Neurobiol. 73(9), 673-687.

Yager, L.M., Garcia, A.F., Wunsch, A.M. \& Ferguson, S.M. (2015) The ins and outs of the striatum: Role in drug addiction. Neuroscience 301, 529-541.

Yamaguchi, T., Sheen, W. \& Morales, M. (2007) Glutamatergic neurons are present in the rat ventral tegmental area. Eur J Neurosci 25, 106-118. 
Zhang, Y., Chen, K., Sloan, S.A., Bennett, M.L., Scholze, A.R., O'Keeffe, S., Phatnani, H.P., Guarnieri, P., Caneda, C., Ruderisch, N., Deng, S., Liddelow, S.A., Zhang, C., Daneman, R., Maniatis, T., Barres, B.A., Wu, J.Q. (2014) An RNA-sequencing transcriptome and splicing database of glia, neurons, and vascular cells of the cerebral cortex. J Neurosci 34, 11929-11947.

\section{Supplement}

Table 1. Differentially expressed $\mathrm{Col}^{*}$ genes in brain regions of male mice with repeated experience of agonistic interactions

\begin{tabular}{|c|c|c|c|}
\hline \multicolumn{2}{|l|}{ Winners } & \multicolumn{2}{|l|}{ Losers } \\
\hline \multicolumn{4}{|c|}{ Hypothalamus } \\
\hline $\begin{array}{l}\text { Col1a1, Col1a2, Col4a2, Col4a5, Col4a6, } \\
\text { Col5a1, Col5a3, Col6a1, Col6a2, Col6a4, } \\
\text { Col9a2, Col9a3, Col11a2,Col16a1, } \\
\text { Col18a1, Col22a1, Col23a1, Col24a1, } \\
\text { Col27a1, Plod3 }\end{array}$ & up & $\begin{array}{l}\text { Col4a1, Col4a2, Col5a3, Col6a3, Col9a2, } \\
\text { Col9a3, Col11a1, Col11a2, Col15a1, } \\
\text { Col16a1, Col18a1, Col22a1, Col23a1, } \\
\text { Col24a1, Col26a1, Col27a1, Plod1, Plod3 } \\
\text { Col1a2, Col3a1, Col13a1, Plod2 }\end{array}$ & up \\
\hline \multicolumn{4}{|c|}{ Midbrain Raphe Nuclei } \\
\hline $\begin{array}{l}\text { Col6a3, Col9a2, Plod3, Plod3 } \\
\text { Col6a2 Col15a1, Col24a1, Col25a1,Plod1 }\end{array}$ & $\begin{array}{l}\text { up } \\
\text { down }\end{array}$ & $\begin{array}{l}\text { Col6a1, Col6a3, Col9a2, Colq, Ccbe1 } \\
\text { Col6a2, Col15a1, Col24a1, Col25a1 }\end{array}$ & $\begin{array}{l}\text { up } \\
\text { down }\end{array}$ \\
\hline \multicolumn{4}{|c|}{ Hippocampus } \\
\hline $\begin{array}{l}\text { Col6a3, Col6a4 } \\
\text { Col8a2, Col11a2, Col16a1 }\end{array}$ & up & $\begin{array}{l}\text { Col1a1, Col1a2, Col3a1, Col5a1, Col5a2, } \\
\text { Col6a1, Col6a2, Col9a2, Col12a1, } \\
\text { Col13a1, Col16a1, Col18a1, Col23a1, } \\
\text { Col27a1, Plod2 } \\
\text { Col6a4 }\end{array}$ & down \\
\hline \multicolumn{4}{|c|}{ Striatum } \\
\hline $\begin{array}{l}\text { Col6a4, Col9a2, Col11a2, Col23a1, } \\
\text { Col27a1 }\end{array}$ & up & $\begin{array}{l}\text { Col1a1, Col1a2, Col3a1, Col5a1, Col5a3, } \\
\text { Col8a1, Col8a2, Col9a2, Col9a3, Col12a1, } \\
\text { Col15a1, Col16a1, Col18a1, Col24a1, } \\
\text { Col25a1, Col27a1, Colq, Cthrc1, Plod1, } \\
\text { Pcolce, Pcolce2 } \\
\text { Col6a1, Col6a4, Col6a5 }\end{array}$ & $\begin{array}{l}\text { up } \\
\text { down }\end{array}$ \\
\hline \multicolumn{4}{|c|}{ Ventral tegmental area } \\
\hline $\begin{array}{l}\text { Col1a1, Col1a2, Col4a1, Col5a2, Col5a3, } \\
\text { Col9a2, Col9a3, Col11a2, Col16a1, } \\
\text { Col23a1, Col24a1, Colq }\end{array}$ & down & $\begin{array}{l}\text { Col25a1, Colgalt2 } \\
\text { Col1a2, Col5a2, Col5a3, Col11a2, } \\
\text { Col24a1, Col27a1, Colq }\end{array}$ & $\begin{array}{l}\text { up } \\
\text { down }\end{array}$ \\
\hline
\end{tabular}


bioRxiv preprint doi: https://doi.org/10.1101/276063; this version posted March 4, 2018. The copyright holder for this preprint (which was not certified by peer review) is the author/funder. All rights reserved. No reuse allowed without permission.

\section{Additional statistics for differentially expressed $\mathrm{Col}^{*}$ genes in brain regions of male mice with repeated experience of agonistic interactions}

In the hypothalamus the $\mathrm{Col}^{*}$ genes increased their expression both in the winners and losers in comparison with the controls as for genes: Col4a2 $(P \leq 0.003$ and $P<0.0001$; $q<$ 0.001 , respectively ), Col5a3 $(P<0.003 ; \mathrm{q}<0.047$ and $P<0.0001 ; \mathrm{q}<0.002$, respectively), Col9a2 ( $P \leq 0.0001 ; \mathrm{q}<0.003$ and $P<0.0003$; $\mathrm{q}<0.004$ respectively), Col9a3 $(P<0.0004$; $\mathrm{q}<0.015$ and $P<0.0001 ; \mathrm{q}<0.001$, respectively $)$, Col11a2 $(P<0.0001 ; \mathrm{q} \leq 0.003$, and $P<$ $0.0001 ; \mathrm{q} \leq 0.001$, respectively), Col16a1 $(P<0.0031 ; \mathrm{q}<0.05$ and $P<0.0001 ; \mathrm{q}<0.001$, respectively), Col18a1 $(P<0.0001 ; \mathrm{q} \leq 0.003$ and $P<0.0001 ; \mathrm{q}<0.001$, respectively), Col22a1 $(P<0.0034$ and $P<0.0041 ; \mathrm{q}<0.025$, respectively), Col23a1 $(P<0.0031$ and $P<$ 0.0099; $\mathrm{q}<0.048$, respectively); Col24a1 $(P<0.011$ and $P<0.0033 ; \mathrm{q}<0.0212$, respectively), Col27a1 $(P<0.0027 ; \mathrm{q}<0.05$ and $P<0.0010 ; \mathrm{q}<0.009)$. Expression of Col1a2 gene was upregulated in the winners $(P<0,043)$, and down regulated in the losers $(P<0.0004 ; \mathrm{q}<0.005)$. In comparison with the controls, the winners expression rate was increased in the Col1a1 $(P<0.005)$, Col4a5 $(P<0.005)$, Col4a6 $(P<0.017)$, Col5a1 $(P<$ $0.017)$, Col6a1 $(P<0.043)$, Col6a2 $(P<0.008)$, Col6a4 $(P<0.009)$ genes. In the losers, expression of the Col4a1 $(P<0.024)$, Col6a3 $(P<0.001, \mathrm{q}<0.001)$, Col11a1 $(P<0.005, \mathrm{q}<$ $0.029)$, Col15a1 $(P<0.047)$ Col26a1 $(P<0.009, \mathrm{q}<0.042)$ genes were increased and the Col3a1 $(P<0.001, \mathrm{q}<0.006)$ and Col13a1 $(P<0.045)$ genes were decreased. In the losers increased expression of the Plod1 $(P<0.008 ; q<0.041)$ and Plod3 $(P<0.0011 ; q<0.010)$ genes as well as decreased expression of Plod2 gene $(P<0.0002 ; \mathrm{q}<0.003)$ was found. In the winners increased expression of Pcolce $(P<0.006)$ and Plod3 $(P<0.008)$ genes was found.

In the midbrain raphe nuclei in the winners and losers expression of the Col6a3 $(P<0.002$ and $P<0.009$, respectively), Col9a2 $(P<0.006$ and $P<0.018$, respectively), genes were increased and Col6a2 ( $P<0.005$ and $P<0.049$, respectively), Col15a1 $(P<0.004$ and $P<$ 0.014 , respectively), Col24a1 (for both $P<0.0001$; $q<0,005)$, Col25a1 $(P<0.039$ and $P<$ 0.001 , respectively) genes were decreased (Figure 2, Supplement Table 2, 4). Additionally in the losers expression of the Col6a1 $(P<0.003)$, Ccbe1 $(P<0.008)$ and Colq $(P<0.007)$ genes were upregulated. In the losers we found increased expression of protocollagen Ccbe1 gene $(P \leq 0.007)$. In the winners decreased expression of $P l o d 1$ gene $(P<0.025)$ and increased expression of Plod2 $(P<0.0095)$ and Plod3 $(P<0.013)$ genes was found.

In the VTA of the winners and losers decreased expression of the Col1a2 $(P<0.022$ and $P$ $<0.001$, respectively), Col5a2 $(P<0.014$ and $P<0.002$, respectively), Col5a3 $(P<0.006$ and $P<0.032$, respectively), Col11a2 $(P<0.001$ and $P<0.012$, respectively), Col24a1(for both $P<0.013)$, Colq $(P<0.0004$ and $P<0.001 ; q<0.007$, respectively) genes were common for both social groups. The Col1a1 $(P<0.016)$, Col4a1 $(P<0.035)$, Col9a2 $(P<$ 0.015), Col9a3 $(P<0.002)$, Col16a1 $(P<0.007)$, Col23a1 $(P<0.004)$ in the winners, and Col27a1 $(P<0.013)$ in the losers specifically decreased their expression. In the losers Col25a1 $(P<0.001 ; \mathrm{q}<0.021)$ and Colgalt2 $(P<0.021)$ genes were upregulated.

In the hippocampus there are no genes that changed their expression in the same direction common for both social groups. However the increased expression of the Col1a1 $(P<$ $0.0001 ; \mathrm{q}<0,005)$, Col1a2 $(P<0.0005 ; \mathrm{q}<0,029)$, Col3a1 $(P<0.0001 ; \mathrm{q}<0,005)$, Col5a1 $(P<0.0001 ; \mathrm{q}<0,005)$, Col5a2 $(P<0.0005 ; \mathrm{q}<0,031)$, Col6a1 $(P<0.0001 ; \mathrm{q}<0,005)$, Col6a2 $(P<0.0001 ; \mathrm{q}<0,005)$, Col9a2 $(P<0.015)$, Col12a1 $(P \leq 0.007)$, Col13a1 $(P<$ 0.033), Col16a1 $P<0.0001 ; q<0,0093)$, Col18a1 $(P<0.0053)$, Col23a1 $(P<0.001 ; q<$ $0,046)$, Col27a1 $(P \leq 0.0003 ; q<0,021)$ was revealed in the losers and Col6a3 $(P<0.0001$; $\mathrm{q}<0,021)$ in the winners. The Col6a4 gene were upregulated in the winners $(P<0.0004)$ and downregulated in the losers $(P<0.0001 ; q<0,01)$. Oppositely, the Col16a1 gene were downregulated in the winners $(P<0.014)$ and upregulated in the losers $(P<0.0001 ; \mathrm{q}<$ 0,009). The Col8a2 $(P<0.021)$ and Col11a2 $(P<0.034)$ genes were specifically 
downregulated in the winners. Expression of the Plod2 gene was decreased in the losers $(P$ $<0.036)$.

In the striatum the Col9a2 and Col27a1 genes were upregulated both in the winners $(P<$ 0.036 and $P<0.048)$ and losers $(P<0.024$ and $P<0.001, q<0.041)$. Specifically the Col11a2 $(P \leq 0.01)$ and Col23a1 $(P<0.002)$ genes in the winners and the Col1a1 $(P<$ $0.0001, \mathrm{q}<0.002)$, Col1a2 $(P<0.0001, \mathrm{q}<0.002)$, Col3a1 $(P<0.0003, \mathrm{q}<0.015)$, Col5a1 $(P<0.0001, \mathrm{q} \leq 0.004)$, Col5a3 $(P<0.027)$, Col8a1 $(P<0.0001, \mathrm{q} \leq 0.003)$, Col8a2 $(P<$ $0.0001, \mathrm{q} \leq 0.003)$, Col9a3 $(P<0.0001, \mathrm{q} \leq 0.003)$, Col12a1 $(P<0.001, \mathrm{q}<0.04)$, Col15a1 $(P<0.027)$, Col16a1( $P<0.009)$, Col18a1 $(P<0.0001, \mathrm{q} \leq 0.003)$, Col24a1 $(P<0.0001, \mathrm{q} \leq$ $0.003)$, Col25a1 $(P<0.039)$, Colq $(P<0.0011)$ genes in the losers were upregulated and the Col6a1 $(P<0.001, \mathrm{q} \leq 0.05)$ and the Col6a5 $(P<0.025)$ were downregulated. The Col6a4 gene was upregulated in the winners $(P \leq 0.002)$ and downregulated in the losers $(P<0.001$, $\mathrm{q} \leq 0.042)$. In the losers we found increased expression of genes $\operatorname{Cthrc1}(P<0.0001, \mathrm{q} \leq$ $0.003)$, Plod1 $(P<0.007)$, Pcolce $(P<0.0001, \mathrm{q} \leq 0.003)$, and Pcolce2 $(P<0.004)$. 